\title{
Ferrites Nanoflowers for Dye Removal Applications
}

\author{
E. Girgis, C. Tharwat ${ }^{*}$ and D. Adel \\ Solid State Physics Department, National Research Centre, 12622 El Buhouth St., Dokki, Cairo, Egypt. \\ Email: christen.tharwat@gmail.com
}

\begin{abstract}
Ferrites nanostructures have been prepared with flower-like shape, as novel cost effective dye removal agent to be used in water purification. $\mathrm{CoFe}_{2} \mathrm{O}_{4}$, and $\mathrm{MnFe}_{2} \mathrm{O}_{4}$ has been prepared via ethylene glycol (EG) mediated self-assembly method. The morphological properties of the assynthesized nano-flower were investigated using transmission electron microscopy (TEM), and selected area electron diffraction (SEAD). Factors influenced shape of nano-flower, such as time, temperature, $\mathrm{pH}$, and urea concentration has been studied. For water purification applications, it is clear that the as-prepared ferrites nano-flowers represent an excellent efficiency to remove polar red 390 dyes from water with efficiency with 46 , and $96 \%$ for both of $\mathrm{CoFe}_{2} \mathrm{O}_{4}$, and $\mathrm{MnFe}_{2} \mathrm{O}_{4}$, respectively.
\end{abstract}

Keywords: Ferrite nanoflower, urea, dye removal, polar red 390 dye, waste water treatment.

\section{Introduction}

The properties of nanoparticles are subject to intense research activity driven by a fundamental interest in the novel physical properties of the nanoscale system and potential industrial application of nanostructure materials. Great attention has been devoted to the nanostructures with different morphology, and dimensionality due to their size and shape dependent photo-catalytical, optical, and photoelectric properties [1-3].

However, it is still a big challenge to develop simple synthetic methods for self assembled structures with designed chemical components and controlled morphologies, which strongly affect the properties of nanomaterials. Magnetic nanoparticles have been extensively studied in diverse fields including catalysis, [2,3] environment protection, [4] sensors, magnetic storage media, and clinical diagnosis and treatment. Various iron oxide structures, such as nanocrystals, particles, cubes, spindles, rods, wires, tubes, and flakes, [5-7] have been successfully fabricated by a variety of methods [8].

The applications of $\mathrm{CoFe}_{2} \mathrm{O}_{4}$ are strongly known by its magnetic properties. For biomedical applications, $\mathrm{CoFe}_{2} \mathrm{O}_{4}$ nanoparticles are required to have high magnetization values, uniform shape, and super-paramagnetic behavior at room temperature. $\mathrm{CoFe}_{2} \mathrm{O}_{4}$, a type of magnetic materials, has a big importance in the basic sciences and technological applications in various fields of electronics [9], photomagnetism [10], catalysis [11], and Ferro-fluids [12]. However, the main difficulty of these classic methods is that the as-prepared nanoparticles are agglomerated with poor control of shape in most cases, which greatly restrict their applications [13].

Also, Manganese ferrite $\left(\mathrm{MnFe}_{2} \mathrm{O}_{4}\right)$ is a well-known magnetic material and its properties are significantly affected by the particle size. It has been found that $\mathrm{MnFe}_{2} \mathrm{O}_{4}$ nanoparticles have higher magnetization values than magnetite nanoparticles [14]. For instance, the coercivity and magnetization of $\mathrm{MnFe}_{2} \mathrm{O}_{4}$ nanoparticles increase with increasing crystalline size [15] and $\mathrm{CoFe}_{2} \mathrm{O}_{4}$ nanoparticles of 20 $\mathrm{nm}$ size exhibit higher coercively (Hc) than bulk $\mathrm{CoFe}_{2} \mathrm{O}_{4}$ [16]. Efficient removal and recovery of hazardous dyes from industrial wastewater receives remarkable attention for its potential environmental impact. Dyes are used at large scale in paper, photography, cosmetics, rubber, plastic, leather and textile industries. Many of these dyes can have acute and or chronic carcinogenic affects on all organisms depending on the amount of exposure time and concentrations. Most techniques described in the literature use adsorbents like clays, sand, fly ash, polymers and activated carbon [17,18]. However, it remains a challenge to separate the activated carbon from the solution.

Various adsorbents have been examined and used for the removal of dyes from waste water. Among the kinds of adsorbents, nano-sized magnetite have attracted interest recently; In particular, magnetite $\left(\mathrm{Fe}_{3} \mathrm{O}_{4}\right)$ and maghemite $\left(\gamma-\mathrm{Fe}_{2} \mathrm{O}_{3}\right)$ have been investigated for several applications such as environmental and bio-applications. In addition to the magnetic properties, low toxicity and price, $\mathrm{Fe}_{3} \mathrm{O}_{4}$ nanoparticles 
have high surface area to volume ratio is associated to their efficiency for surface chemical modification, and can show enhanced capacity for heavy metal uptake in water treatment procedures [19].

In this paper we report the synthesis of flowerlike Cobalt Ferrite and Manganese Ferrite nanostructures by an ethylene glycol (EG)-mediated process and their application as a low cost adsorbent for the removal of polar red 390 dye from aqueous solutions with high efficiency.

\section{Experimental work}

\section{$2.1 \quad$ Materials}

$\mathrm{FeCl}_{3} \cdot 6 \mathrm{H}_{2} \mathrm{O}$ (purchased from ALPHA CHEMIKA - India - 97\%), $\mathrm{CoCl}_{2} \cdot 6 \mathrm{H}_{2} \mathrm{O}$ (purchased from WINLAB - UK - 98\%), Urea (purchased from FISCHER - India - 90\%), Tetra-butyl ammonium bromide (purchased from MERCK - Germany - $\geqslant 98 \%$ ), Ethylene Glycol (purchased from ElGOUMHOURIA Company - Cairo-Egypt - 98\%), and $\mathrm{MnCl}_{2} \cdot 6 \mathrm{H}_{2} \mathrm{O}$ (purchased from WINLAB - UK $99 \%)$.

\subsection{Preparation of ferrites Nano-flowers}

In a typical procedure; to bottomed flask a mixture of (100 mM) $\mathrm{FeCl}_{3} \cdot 6 \mathrm{H}_{2} \mathrm{O},(100 \mathrm{mM}) \mathrm{CoCl}_{2} \cdot 6 \mathrm{H}_{2} \mathrm{O}$, $0.2 \mathrm{~g}(250 \mathrm{mM})$ urea, and $1.4 \mathrm{ml}(300 \mathrm{mM})$ of Tetra-butyl ammonium bromide was added, $18 \mathrm{ml}$ ethylene glycol was also added. And an orange solution has been obtained. Then the mixture was left under vigorous stirring at $\mathrm{pH}$ of 2.8 using $\mathrm{NaCl}$ solution $(1 \mathrm{M})$, and refluxing at $80{ }^{\circ} \mathrm{C}$. After 30 min, a precipitate has been formed where the color of mixture turned to deep orange color. After a further 60 min, the mixture became completely red, indicating the formation of hierarchical nanostructures. After refluxing for $1 \mathrm{~h}$, the reaction was stopped and the mixture was cooled to room temperature. The precipitate was collected by centrifugation and washed with ethanol four times. The same steps were repeated for $(100 \mathrm{mM}) \mathrm{MnCl}_{2} \cdot 6 \mathrm{H}_{2} \mathrm{O}$ instead of $\mathrm{CoCl}_{2} \cdot 6 \mathrm{H}_{2} \mathrm{O}$ then the mixture turned yellow after $60 \mathrm{~min}$.

\subsection{Dye removal experiment}

Dye recovery using flower-like shape of Ferrites nanostructures was conducted by incubating the nanoflower in polar red 390 dye (where its chemical family is: Mono-azo), where an accurate weighed quantity (0.2 gm of the dye in $150 \mathrm{ml}$ distilled water) was used to prepare a stock solution. The solutions for adsorption tests were prepared from the stock solution to known concentrations by successive dilutions. $5 \mathrm{ml}$ of solution containing nanostructure was added to a fixed volume of $25 \mathrm{ml}$ of previously prepared dye. The mixture was gently shacked in a shaker water bath at $200 \mathrm{rpm}$. After taking a read using UV-Visible spectroscopy, all the results has been tabulated. The $\mathrm{pH}$ value for both nanoflowers before adding the red polar dye was 2.8 while after adding the dye was 6.2 and 7 for $\mathrm{CoFe}_{2} \mathrm{O}_{4}$ and $\mathrm{MnFe}_{2} \mathrm{O}_{4}$, respectively.

\subsection{Characterization}

Morphological properties of the as-prepared flower-like nanoparticles have been investigated using selected area electron diffraction (SAED) equipped with a high-resolution transmission electron microscope (HR-TEM, JEOL, JEM-2010). The UV-visible absorption spectroscopy for the as-prepared samples after adding dye has been investigated using Ocean Optics USB 2000 spectrometer. The absorption was recorded within the appropriate scan range from 400 to $600 \mathrm{~nm}$.

\section{Results}

\subsection{Structural and compositional analysis}


It is important to explore the elemental distribution of $\mathrm{Mn}$ and $\mathrm{Co}$ in the nano-flower. An energy dispersive x-ray analysis (EDXA) mapping measurement is a powerful technique which allows us to determine the exact atomic ratio of elements in the prepared samples during the imaging of the flowers. Figure (1) represents the EDXA data for each of Mn, Co and Fe, where Co and Mn are homogeneously mixed, indicating the formation of an alloy, Figure (1.a) confirmed that the flowerlike sample consisted of $\mathrm{Co}$ and Fe, where Figure (1.b) confirmed that the flowerlike sample consisted of Mn and Fe.

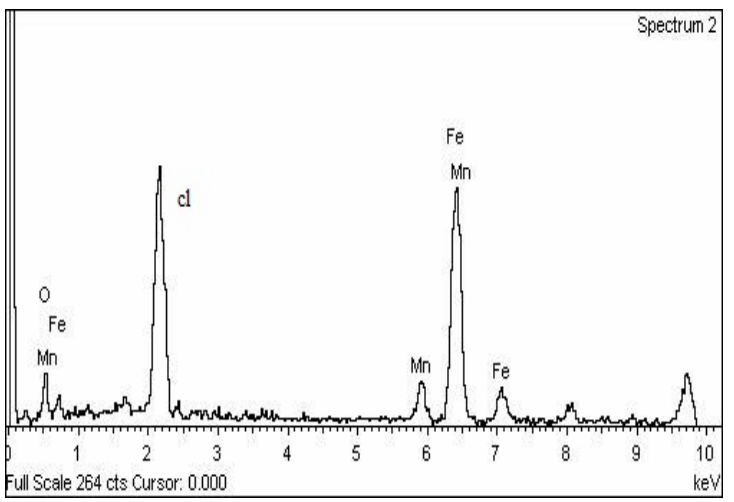

(a)

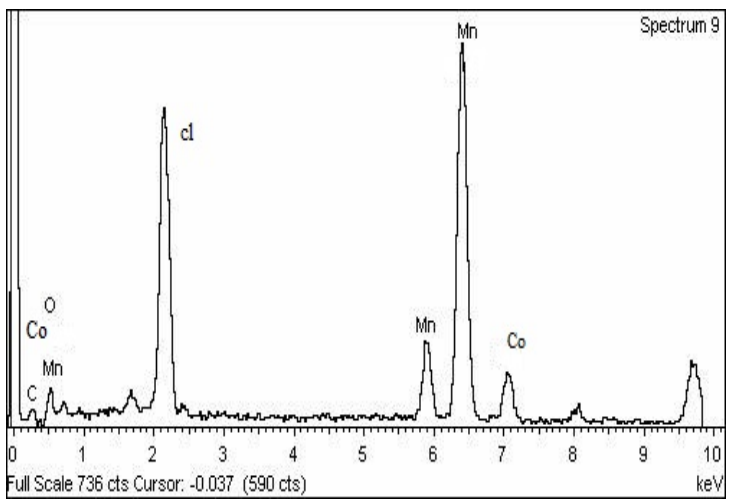

(b)

Figure 1. EDX analysis for: a) $\mathrm{CoFe} 2 \mathrm{O} 4$, b) MnFe2O4.

\subsection{Factors affecting nano-flower formation}

\subsubsection{Effect of time}

Time is considered to be one of the important factors influencing in the formation of the nanoparticles shape. Time-dependent experiments were carried out during which samples were collected at different time intervals from the reaction mixture once a precipitate appeared in the clear solution. It is clear that the shape gradually changes by varying time. Figure (2.a \& 2.b) shows the general morphologies of the cobalt ferrite nanostructures after $5 \mathrm{~min}$. \& $60 \mathrm{~min}$. respectively, where in figure (2.a) nanospheres of average $261 \mathrm{~nm}$ appears, while figure (2.b) shows that after $60 \mathrm{~min}$. of reaction nanoflowers clusters appears in scale of $1 \mu \mathrm{m}$.

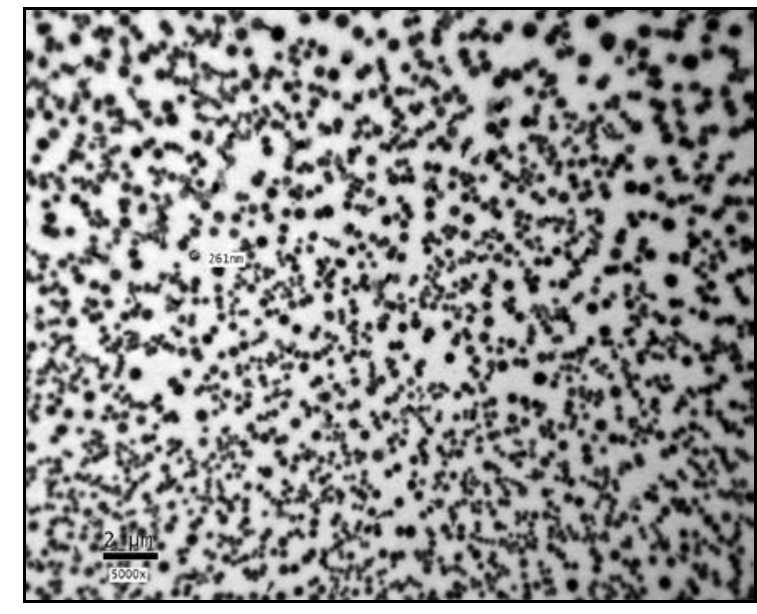

(a)

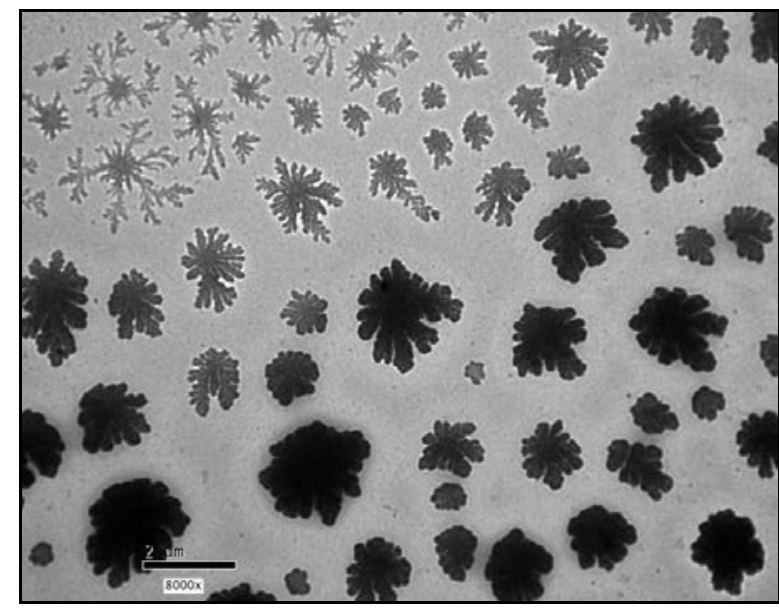

(b)

Figure 2. Nuclei growth of $\mathrm{CoFe}_{2} \mathrm{O}_{4}$ nanoflower over 1 hour: a) nanospheres after 5 min. growth, b) final shape of $\mathrm{CoFe}_{2} \mathrm{O}_{4}$ Nanoflower after one hour of the reaction. 
Figure (3) shows the general morphologies of the manganese ferrite nanostructures about $100 \mathrm{~nm}$ after $60 \mathrm{~min}$. of the reaction. The same steps repeated during the formation of $\mathrm{MnFe}_{2} \mathrm{O}_{4}$ nanoflower with the same conditions. It's obvious that at after $60 \mathrm{~min}$. of reaction a clear nanoflower structure was appearing as in Figure (2.b).

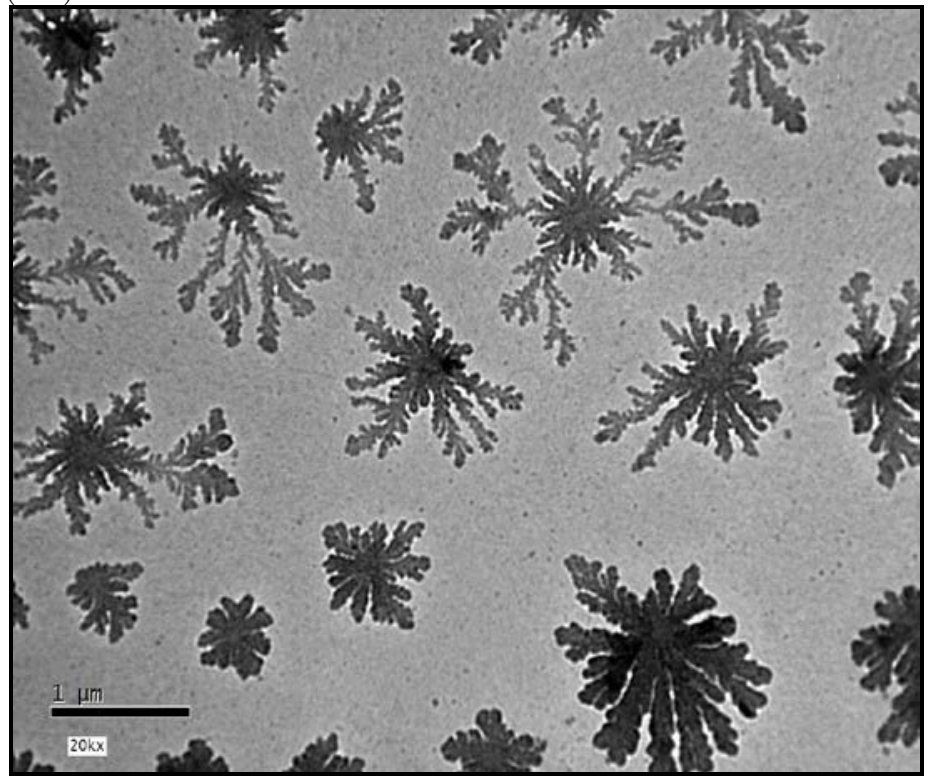

Figure 3. Transmission electron microscopy (TEM) images of $\mathrm{MnFe}_{2} \mathrm{O}_{4}$ nanoflower.

To investigate HRTEM and the crystal structure, selected area electron diffraction (SAED) patterns were recorded and represented in Figures (4) and (5) respectively. The SAED patterns show that, the diffraction spots are superimposed on the rings indicating the polycrystalline structure of the flowers shape. It's clear that we start observing nanoflowers after $60 \mathrm{~min}$. of the reaction, which support that time is an important factor in our recipe.

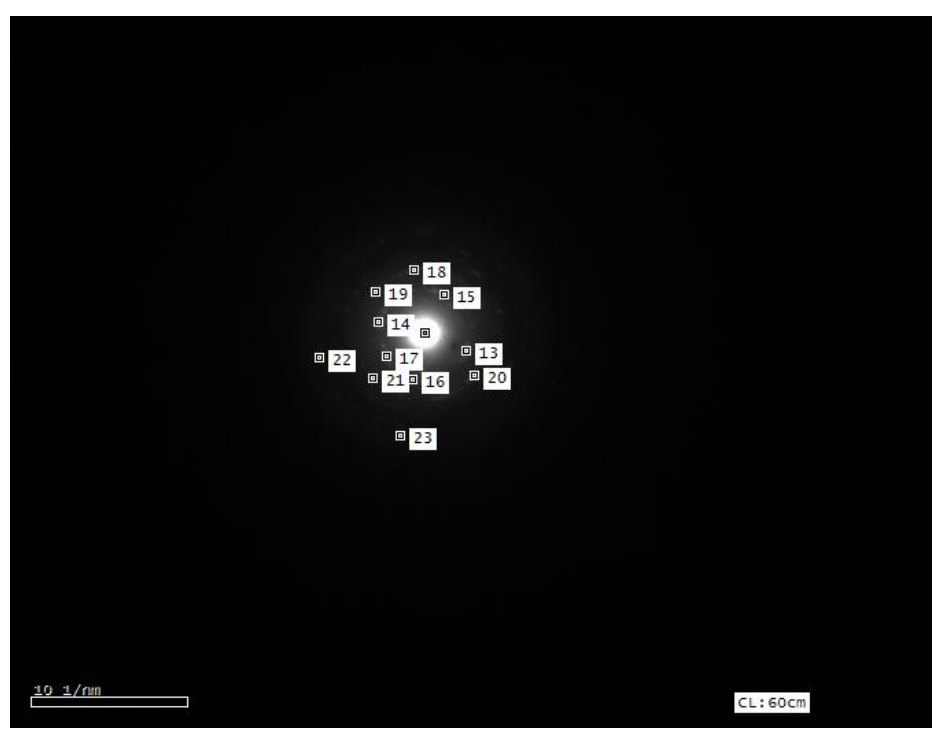

Figure 4. SAED pattern of the $\mathrm{CoFe}_{2} \mathrm{O}_{4}$ nanoflower. 


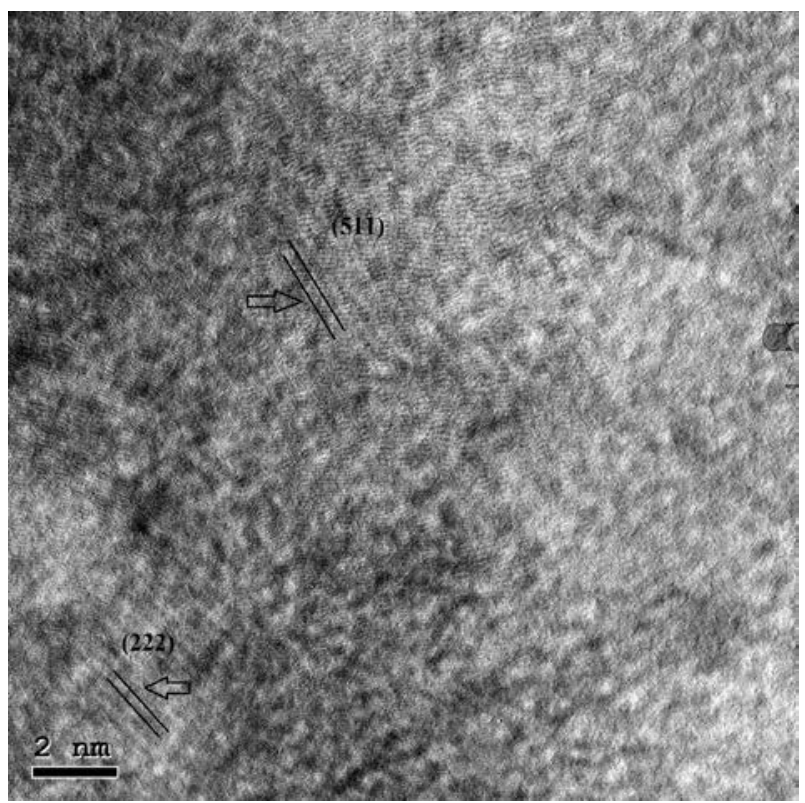

Figure 5. HRTEM micrograph for prepared $\mathrm{CoFe}_{2} \mathrm{O}_{4}$ nanoparticles.

\subsubsection{Effect of temperature}

Another parameter which can effect on the formation of flower-like nanostructure is the reaction temperature. In this study; we carry out the reaction under several exposure temperatures of the experiment to study the effect of thermodynamics on the nanoflower structure. As shown in Figure (6) the shape of $\mathrm{CoFe}_{2} \mathrm{O}_{4}$ nanoflower was affected by changing the reaction temperature to $140^{\circ} \mathrm{C}$ instead of $80^{\circ} \mathrm{C}$ as the previous conditions. At $80^{\circ} \mathrm{C}$ clear flower nanostructures has been obtained as shown in Figure (6.b) with scale $2 \mu \mathrm{m}$, while at higher temperature $\left(140^{\circ} \mathrm{C}\right)$ no nanoflower structure was found as shown in Figure (6.a).

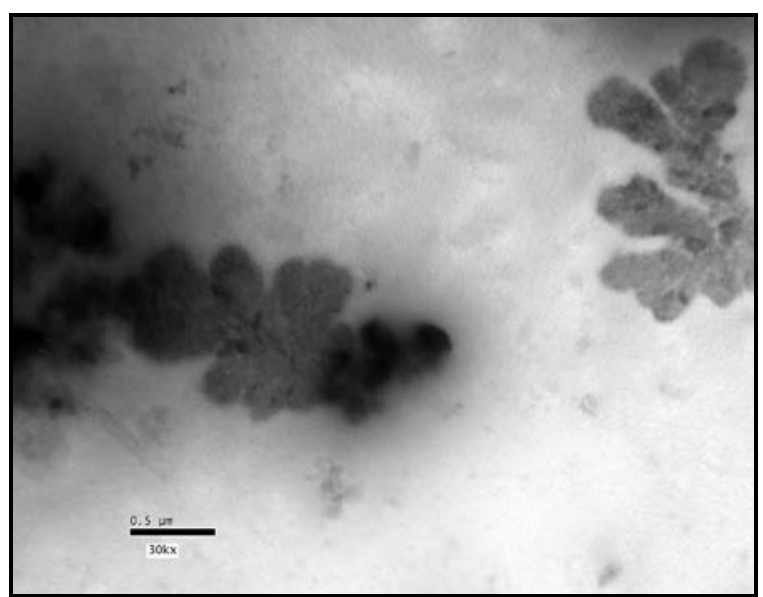

(a)

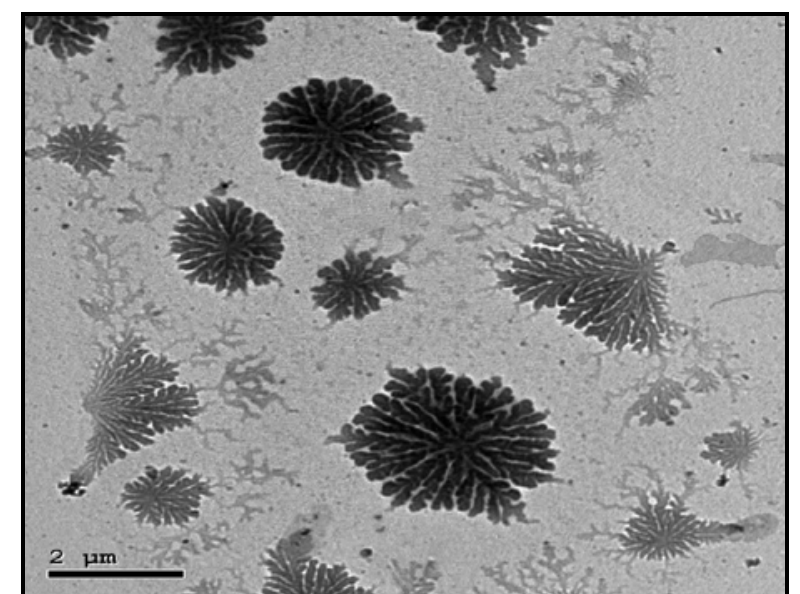

(b)

Figure 6. Transmission electron microscopy image of $\mathrm{CoFe}_{2} \mathrm{O}_{4}$ prepared at: a) $140^{\circ} \mathrm{C}$, b) $80^{\circ} \mathrm{C}$.

\subsubsection{Effect of $\mathrm{pH}$}

The influence of $\mathrm{pH}$ on nanoflower formation was studied over a range of $\mathrm{pH}$ values 2.8 and 4.8 . Figure (7.a) shows TEM image of $\mathrm{MnFe}_{2} \mathrm{O}_{4}$ nanoparticles with $\mathrm{pH} 4.8$ where acetic acid and sodium chloride were used to adjust pH value during preparation, while Figure (7.b) shows TEM image of $\mathrm{MnFe}_{2} \mathrm{O}_{4}$ nanoparticles for the sample with $\mathrm{pH} 2.8$ at the same scale $2 \mu \mathrm{m}$. It is obvious that when $\mathrm{pH}$ value is 2.8 
it gives a clear nanoflower structure, counter to $\mathrm{pH} 4.8$ no definite nanostructure have observed, so $\mathrm{pH}$ seems to be an important parameter during the preparation.

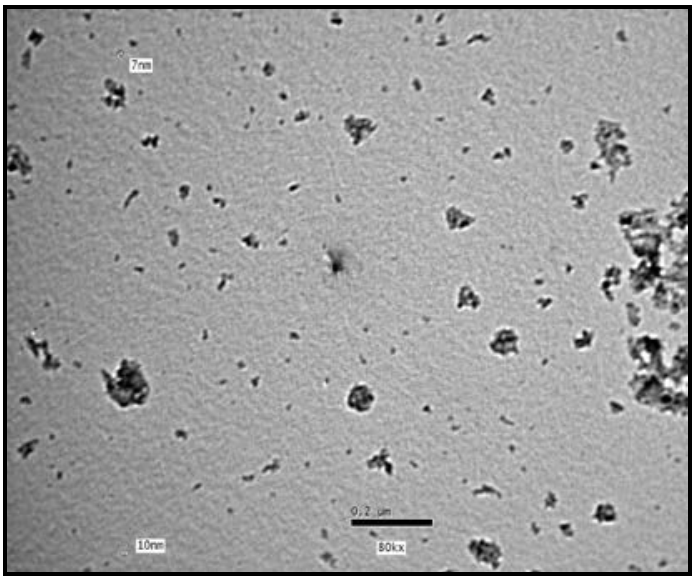

(a)

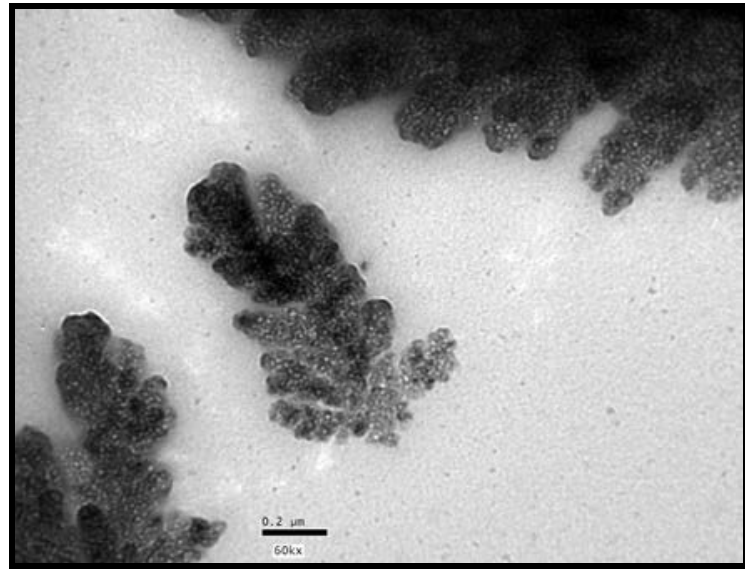

(b)

Figure 7. Transmission electron microscopy (TEM) image of a) $\mathrm{MnFe}_{2} \mathrm{O}_{4}$ prepared at $\mathrm{pH} 4.8$ after 60 min, b) $\mathrm{MnFe}_{2} \mathrm{O}_{4}$ prepared at $\mathrm{pH} 2.8$ after 60 min.

\subsubsection{Effect of Urea concentration}

Finally; the role of urea was found to be very critical in this synthesis method. In a controlled experiment, when no urea was added under the same reaction conditions, no apparent precipitate was collected. Urea is often used to provide a steady $\mathrm{OH}^{-}$ion supply through urea hydrolysis.

Figure (8.a) shows TEM image of $\mathrm{CoFe}_{2} \mathrm{O}_{4}$ nanoparticles sample at $1 \mathrm{mM}$ of urea after 60 minutes, while Figure (8.b) shows TEM image of the same sample at $250 \mathrm{mM}$ of urea at same scale $1 \mu \mathrm{m}$. It is obvious that when the concentration of urea is $250 \mathrm{mM}$ it gives an obvious nanoflowers structure, while $1 \mathrm{mM}$ gives nanospheres of size ranges between $123 \mathrm{~nm}$ to $354 \mathrm{~nm}$. When urea is added, the $\mathrm{OH}^{-}$formed by urea hydrolysis would neutralize the $\mathrm{HCl}$ and allow the coordination reaction to be completed. So urea concentration seems to be an important parameter during the preparation.

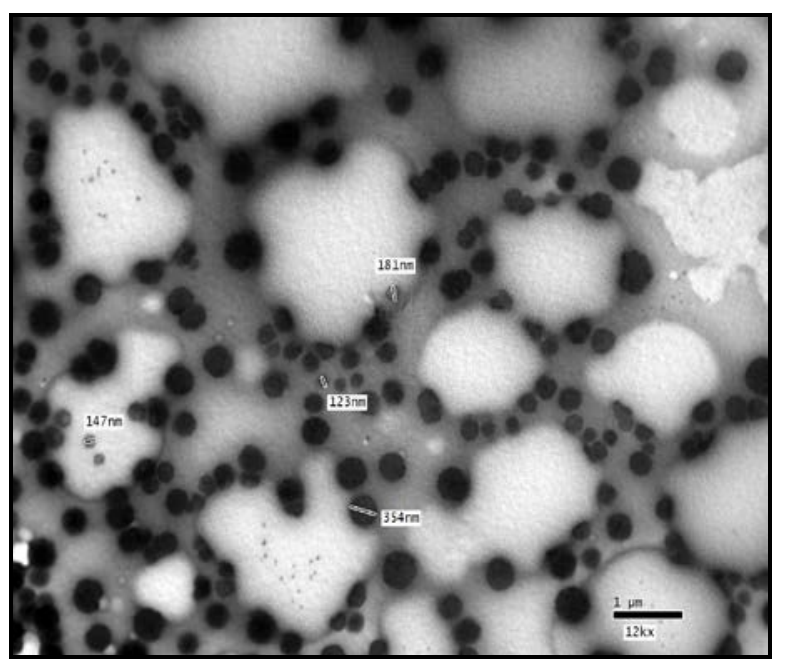

(a)

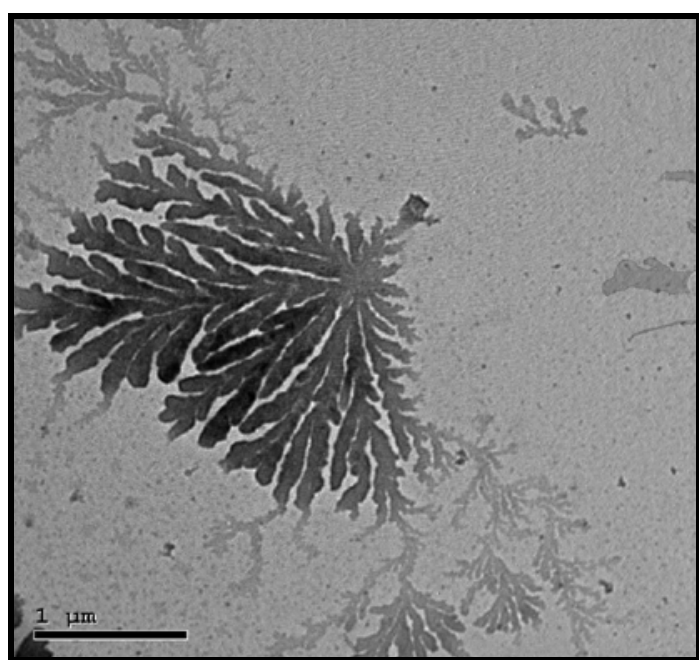

(b)

Figure 7. Transmission electron microscopy (TEM) image of: a) $\mathrm{CoFe}_{2} \mathrm{O}_{4}$ prepared at $(1 \mathrm{mM})$ of urea after $60 \mathrm{~min}$, b) $\mathrm{CoFe}_{2} \mathrm{O}_{4}$ prepared at $(250 \mathrm{mM})$ of urea after $60 \mathrm{~min}$. 


\section{Dye removal}

Figure (9) shows the UV-visible absorption spectrum at room temperature of the as-synthesized nanostructures with the polar red as reference dye. It is obvious that there is a shift in the curve of the two samples with respect to the curve of the polar red dye. Table (1) explains the condition of every nanoflower as $\mathrm{pH}$ value before and after dye added, removal time, and finally the percent-age of dye removal for the both nanoflowers.

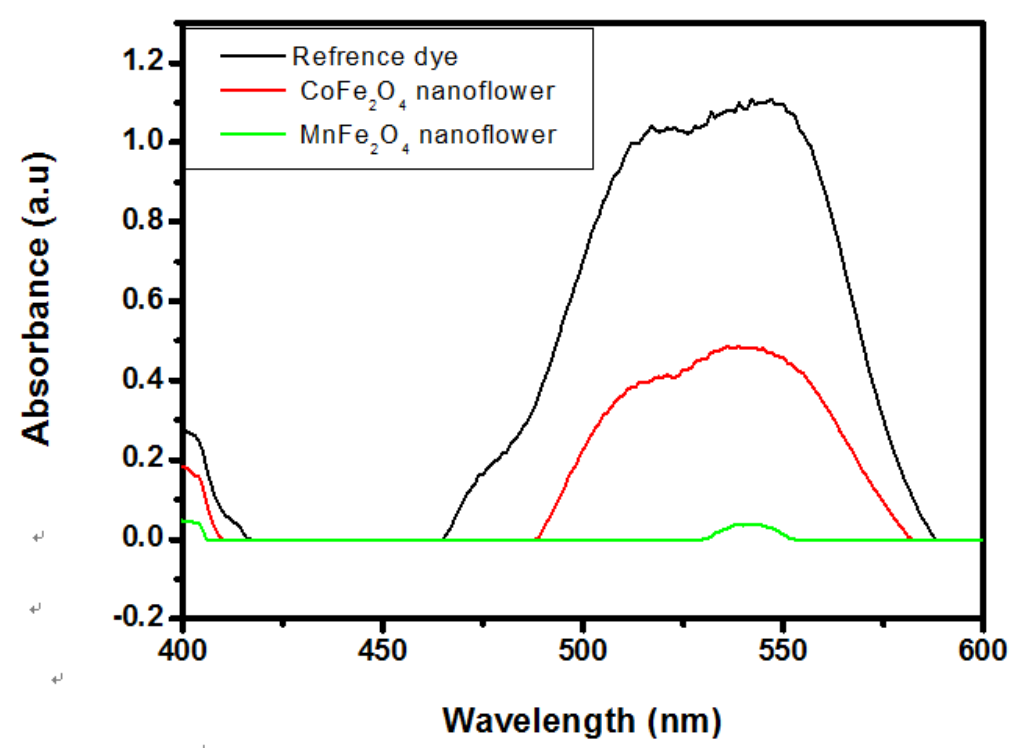

Figure 5. Visible absorption spectrum of $\mathrm{CoFe}_{2} \mathrm{O}_{4}$ and $\mathrm{MnFe}_{2} \mathrm{O}_{4}$ nanoflower versus the red polar 390 dye.

Table 1. Design for the Optimization of polar red Dye's Removal

\begin{tabular}{cccccc}
\hline Number & $\begin{array}{c}\text { Type of } \\
\text { nanoflower }\end{array}$ & $\begin{array}{c}\mathrm{pH} \text { before dye } \\
\text { added }\end{array}$ & $\begin{array}{c}\mathrm{pH} \text { after dye } \\
\text { added }\end{array}$ & $\begin{array}{c}\text { Removal } \\
\text { time }\end{array}$ & $\begin{array}{c}\% \text { of dye } \\
\text { removal }\end{array}$ \\
\hline 1 & $\mathrm{CoFe}_{2} \mathrm{O}_{4}$ & 2.8 & 6.2 & $120 \mathrm{~min}$ & $46 \%$ \\
2 & $\mathrm{MnFe}_{2} \mathrm{O}_{4}$ & 2.8 & 7 & $120 \mathrm{~min}$ & $96 \%$ \\
\hline
\end{tabular}

\section{Conclusion}

In conclusion; $\mathrm{CoFe}_{2} \mathrm{O}_{4}$ and $\mathrm{MnFe}_{2} \mathrm{O}_{4}$ with flower-like shape have been prepared via a facile chemical route, using non-toxic and inexpensive reagents. The morphological characterization analysis proved the formation of nanoflowers. Also, EDXA measurements verified the presence of both of $\mathrm{Co}, \mathrm{Fe}$, and $\mathrm{Mn}$ elements inside the formed nanostructures. In this study, it was found that the lowest concentration of

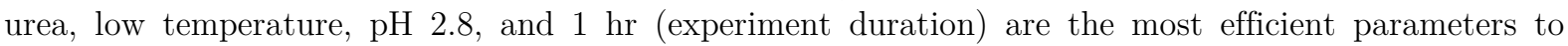
synthesize $\mathrm{CoFe}_{2} \mathrm{O}_{4}$ and $\mathrm{MnFe}_{2} \mathrm{O}_{4}$ nanoflower alloys.

Also, the results showed that these nanoparticles can be used as an effective adsorbent for removing dye and could effectively remove high concentrations of the polar red dye in a short contact time (120 minutes), where the efficiency was $46 \%$ for $\mathrm{CoFe}_{2} \mathrm{O}_{4}$ and $96 \%$ for $\mathrm{MnFe}_{2} \mathrm{O}_{4}$. This supports using of $\mathrm{MnFe}_{2} \mathrm{O}_{4}$ nanoflowers instead of $\mathrm{CoFe}_{2} \mathrm{O}_{4}$ for dye removal based on its better efficiency.

The present approach is considered to be a very simple method for synthesis of flower nanostructures and these nanoparticles may have a good prospect in scientific and industrial applications in the future. 
Acknowledgment: We thank Solid State Physics Department, National Research Centre, 12622 El

Buhouth St., Dokki, Cairo, Egypt.

\section{References:}

1. HOU Xiang-yu, FENG Jing, LIU Xiao-han, and ZHANG Mi-lin, "Comparable Studies of Adsorption and Magnetic Properties of Ferrite MnFe2O4 Nanoparticles, Porous Bulks and Nanowires", CHEM. RES. CHINESE UNIVERSITIES (2011), 27(4), p.p.543-546.

2. L. Q. Mai, Y. H. Gu, C. H. Han, B. Hu, W. Chen, P. C. Zhang, L. Xu, W. L. Guo, Y. Dai,"Orientated LangmuirBlodgett Assembly of VO2 Nanowires", Nano Letters, 92 (2009) pp. 826 - 830.

3. Cao F, Shi WD, Zhao LJ, Song SY, Yang JH, Lei YQ, Zhang HJ. "Hydrothermal synthesis and high photocatalytic activity of 3D wurtzite ZnSe hierarchical nanostructures", J Phys Chem C.(2008);112: p.p. 1709517101.

4. J. L. Zhang, Y. Wang, H. Ji, Y. G. Wei, N. Z. Wu, B. J. Zuo, Q. L.Wang, J. Catal. "Magnetic nanocomposite catalysts with high activity and selectivity for selective hydrogenation of ortho-chloronitrobenzene",(2005), 229, p.p. 114-118.

5. O. Shekhah, W. Ranke, A. Schule, G. Kolios, R. Schlogl, "Styrene synthesis : high conversion over unpromoted iron oxide catalysts under practical working conditions" (2003), Angew. Chem. Int. Ed., 42, p.p. 5760-5763.

6. E. Girgis, D. Adel, C. Tharwat, O. Attallah and K.V. Rao, "Cobalt ferrite nanotubes and porous nanorods for dye removal", Advances in Nano Research, Vol. 3, No. 2 (2015) p.p.111-121 .

7. P. Li, D.E. Miser, S. Rabiei, R.T. Yadav, M.R. Hajaligol, "The removal of carbon monoxide by iron oxide nanoparticles", Appl. Catal., B - Environ., 43 (2003), pp. 151-162.

8. K. Woo, H. J. Lee, J. P. Ahn, Y. S. Park, "Sol-gel mediated synthesis of Fe2O3 nanorods", (2003), Adv. Mater., 15, p.p. 1761-1764.

9. X. G. Wen, S. H. Wang, Y. Ding, Z. L. Wang, S. H. Yang, "controlled growth of large-area, uniform, vertically aligned arrays of alpha-Fe2O3 nanobelts and nanowires" (2005), J. Phys.Chem. B, 109, p.p. 215-220.

10. C. J. Jia, L. D. Sun, Z. G. Yan, L. P. You, F. Luo, X. D. Han, Y. C.Pang, Z. Zhang, C. H. Yan, "Singlecrystalline iron oxide nanotubes", (2005) ,Angew. Chem. Int. Ed., 44, p.p. 4328-4333.

11. YW Zhu, T Yu, CH Sow, YJ Liu, ATS Wee, XJ Xu, CT Lim, and JTL Thong, "Efficient field emission from alpha-Fe2O3 nanoflakes on an atomic force microscope tip",(2005) Applied Physics Letters, 87, 23103,p.p. 1-3.

12. Sugimoto, M., The past, present and future of ferrites. J. Am. Ceram. Soc., (1999), 82, p.p. 269-280.

13. A.K. Giri, E.M. Kirkpatrick, P. Moongkhamklang, S.A. Majetich and V. G. Harris, "Photomagnetism and structure in cobalt ferrite nanoparticles ,(2002), Appl. Phys. Lett. 80, p.p. 2341.

14. T. Mathew, S. Shylesh, B.M. Devassy, M. Vijayaraj, C.V.V.Satyanarayana, B.S. Rao, C.S. Gopinath," Selective production of orthoalkyl phenols on $\mathrm{Cu} 0.5$ Co $0.5 \mathrm{Fe} 2 \mathrm{O} 4$ : a study of catalysis and characterization" (2004), Appl.Catal. A-Gen. 273, p.p.35-45.

15. G.V.M. Jacintho, A.G. Brolo, P. Corio, P.A.Z. Suarez, J.C. Rubim," Structural investigation of MFe2O4 $(\mathrm{M}=$ Fe, Co) magnetic fluids", (2009) , J. Phys. Chem. C 113, p.p. 7684-7691.

16. S. Bhattacharyya, J.P. Salvetat, R. Fleurier, A. Husmann, T. Cacciaguerra, M.L. Saboungi," One step synthesis of highly crystalline and high coercive cobalt-ferrite nanocrystals", (2005) ,Chem. Commun. 38, p.p. 4818-48120.

17. Espantaleon, A.G. Nieto, J.A. Fernandez, M. Marsal," "Use of Activated Clays in the Removal of Dyes and Surfactants from Tannery Waste Waters" (2003), A. Appl Clay Sci. 24:p.p. 105-110.

18. Khraisheh, M.A.M. \& Alg-Houti," Enhanced dye adsorption by micro emulsion-modified calcined diatomite $(\mu \mathrm{E}-$ CD) Adsorption", (2005), M.S. Adsorption. 11 p.p. 547-549.

19. Liang-Shu Zhong, Jin-Song Hu, Han-Pu Liang, An-Min Cao, Wei-Guo Song, and Li-Jun Wan," Self-assembled 3D flowerlike nanostructures of iron oxide from ferric chloride and their applications in water treatment", (2006), Adv. Mater., 18, p.p. 2426-2431. 